\title{
Phosphorylation as Conformational Switch from the Native to Amyloid State - Trp-Cage as Protein Aggregation Model
}

József Kardos ${ }^{\dagger, t, *}$, Bence Kiss ${ }^{\dagger, \S}$, András Micsonai ${ }^{\dagger}$, Petra Rovó ${ }^{\S}$, Dóra K. Menyhárd ${ }^{\S, \|}$, János Kovács ${ }^{\varpi,}$, Györgyi Váradi ${ }^{\perp}$, Gábor K. Tóth ${ }^{\perp}$, and András Perczel ${ }^{\S, \|, *}$

${ }^{\dagger}$ Department of Biochemistry, ${ }^{*}$ MTA-ELTE NAP B Neuroimmunology Research Group, and

ๆ'Department of Anatomy, Cell and Developmental Biology, Institute of Biology Eötvös Loránd University, Pázmány P. sétány 1/C, Budapest, H-1117 Hungary

${ }^{\S}$ Laboratory of Structural Chemistry and Biology and ${ }^{\|}$MTA-ELTE Protein Modelling Research Group, Eötvös Loránd University, Pázmány P. sétány 1/A, Budapest, H-1117 Hungary

${ }^{\perp}$ Department of Medical Chemistry, University of Szeged, Dóm tér 8, Szeged, H-6720 Hungary 


\section{ABSTRACT}

The 20 residue long Trp-cage miniprotein is an excellent model both for computational and experimental studies of protein folding and stability. Recently, a great attention emerged to study disease-related protein misfolding, aggregation and amyloid formation, with the aim of revealing their structural and thermodynamic background. Trp-cage is sensitive to both environmental and structure-modifying effects, and aggregates with ease upon structure destabilization and thus, it is an ideal model of aggregation and amyloid formation. Here, we characterize the amyloid formation of several sequence modified and side-chain phosphorylated Trp-cage variants. We applied NMR, CD, FTIR spectroscopy, MD simulations, transmission electron microscopy in conjunction with thioflavin-T fluorescence measurements to reveal the structural consequences of side-chain phosphorylation. We demonstrate that the native fold is destabilized upon serine phosphorylation and the resultant highly dynamic structures form amyloid-like ordered aggregates with high intermolecular $\beta$-structure content. The only exception is the D9S(P) variant which follows an alternative aggregation process by forming thin fibrils, presenting a CD spectrum of PPII helix, and showing low ThT binding capability. We propose a complex aggregation model for these Trp-cage miniproteins. This model assumes an additional aggregated state, a collagen triple helical form which can precede amyloid formation. The phosphorylation of a single serine residue serves as a conformational switch, triggering aggregation, otherwise mediated by kinases in cell. We show that Trp-cage miniprotein is indeed a realistic model of larger globular systems of composite folding and aggregation landscapes and helps us to understand the fundamentals of deleterious protein aggregation and amyloid formation. 
Keywords: Trp-cage miniprotein, protein aggregation, misfolding, amyloid formation, polyproline-helix, CD spectroscopy.

\section{INTRODUCTION}

Increasing number of diseases are linked to amyloid aggregate formation, occurring seemingly independently of the amino acid sequence. ${ }^{1}$ Apart from the disease-related amyloids, some functional amyloid proteins has also been discovered which play an important role e.g. in melanin synthesis or in bacterial biofilm formation. ${ }^{2}$ Other studies suggested that the amyloid aggregate state might represent the global energy minimum in the folding process of many native proteins $^{3}$, therefore the investigation of the amyloid protein structures and the mechanisms through they are formed is of fundamental importance.

The main structural characteristic of amyloid aggregates are the strongly H-bonded cross- $\beta$ structure where the $\beta$-strands are oriented perpendicular to the fiber axis (e.g. in amyloid- $\beta$, IAPP, $\alpha$-synuclein, Huntingtin). ${ }^{4,5}$ These $\beta$-strands can be parallel or antiparallel, in-register or out-of-register depending on the protein's primary sequence. ${ }^{4,6}$ From a mechanistical point of view, the oligomerization is initiated by specific sequences through yet unknown intermediate states which then mature into toxic aggregates of various morphologies and further into plaques, deposits and tangles. ${ }^{7,8}$ Much more is known about their macroscopic structure, pathologic description and diagnostic epitopes, but the mechanistic details of the process which leads to amyloid formation is still unclear at the molecular and atomic level.

The role of posttranslational modifications (such as truncation or phosphorylation) in amyloidoses and the underlying molecular pathomechanism is poorly understood. ${ }^{9-12}$ There is increasing evidence that abnormal- or hyperphosphorylation might be the driving force in the

intracellular aggregation of tau protein ${ }^{13}, \quad \alpha$-synuclein ${ }^{14-20}$ and amyloid- $\beta$ peptide. ${ }^{21-25}$ The 
phosphorylation at specific Ser or Thr residues might promote the nucleation-dependent oligomerization and thus aggregation of these proteins by increasing the $\beta$-sheet character of the modified sequences. ${ }^{21}$ However, it remains unclear to what extent is the secondary structure affected and how the inter- and intramolecular interactions are modified due to the side-chain phosphorylation.

Therefore we aimed to study the aggregation process of a model system (Trp-cage) phosphorylated at different Ser side chains to gain insights into the mechanistic and atomic details of amyloid aggregate formation. Trp-cage is the smallest protein-like molecule which could realistically model larger globular proteins or domains. ${ }^{26}$ It consist of only 20 residues but still folds into a well-defined tertiary structure ${ }^{26}$ through a complex folding pathway. ${ }^{27}$ Due to its small size it is an excellent model system for both experimental ${ }^{26,28-32}$ and computational studies. ${ }^{33,34}$ Recent studies however focus mainly on the native structure, folding and stability of the system while none of them investigates intermolecular interactions which could lead to oligomerization or aggregation of Trp-cage.

Here we present a mechanistic insight into the aggregation processes of different Trp-cage variants. Using various spectroscopic methods we have tested how the phosphorylation of specific serine side chains induces conformational switches and thus initiates native to amyloid fibril formation. We have synthesized and purified three Ser- $\mathrm{PO}_{4} \mathrm{H}_{2}$-derivatives of Trp-cage (Fig. 1), namely that of Tc5b_13S(P), Tc5b_14S(P), and Tc5b_20S(P). In addition, the intramolecular salt bridge forming $\mathrm{D}^{9}$ of Tc5b was altered and thus, Tc5b_D9E, Tc5b_D9S and Tc5b_D9S(P) were also synthesized and studied (short names presented in Fig. 1 will be used throughout the manuscript). The secondary structure contents of the monomer and aggregated forms were monitored using NMR chemical shift deviations, and Circular Dichroism (CD) and Fourier 
Transform Infrared (FTIR) spectroscopy. The amyloid properties and morphologies of the aggregates were studied by thioflavin-T (ThT) fluorescence and transmission electron microscopy (TEM).
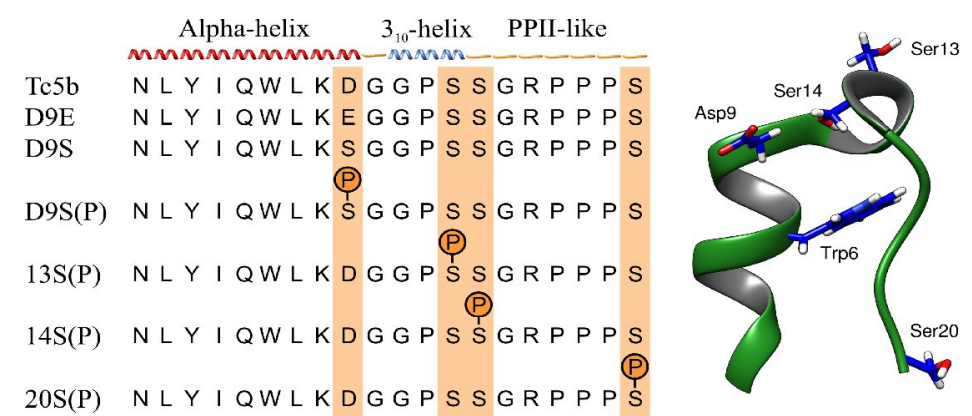

Figure 1. (Left) Amino acid sequences of Trp-cage variants. The secondary structure composition in the "native" form of Trp-cage is indicated at the top. (Right) Backbone scheme of the 3D-fold of a typical Trp-cage composed of an $\alpha$ - and a $33_{10}$-helix, terminated by the proline rich segment in PPII-like conformation as determined by NMR spectroscopy. ${ }^{26,}{ }^{29}$ We use the short names of Trp-cage variants throughout the text as follows: Tc5b_D9E, D9E; Tc5b_D9S, D9S; Tc5b_D9S(P), D9S(P); Tc5b_S13S(P), 13S(P); Tc5b_S14S(P), 14S(P); Tc5b_S20S(P), 20S(P).

\section{MATERIALS AND METHODS}

Peptide synthesis and purification. Peptides were synthesized by solid-phase technique utilizing Fmoc chemistry as described previously. ${ }^{29}$ Phosphopeptides were prepared by the standard global method; serine residue to be phosphorylated was built into the sequence without side-chain protection. Phosphorylation was carried out after the assembly of the peptide chain on the solid phase by the phosphoramidite method. ${ }^{35}$ The crude peptides were purified by semipreparative RP-HPLC. Detailed procedure of peptide synthesis and purification is presented in Supporting Material.

Dissolution of Trp-cage samples and aggregate formation. Peptide samples were dissolved in $\mathrm{H}_{2} \mathrm{O}$ at a concentration of $2-10 \mathrm{mg} \cdot \mathrm{ml}^{-1}$. The $\mathrm{pH}$ was measured by a NOP-0823P microelectrode (Radelkis, Budapest, Hungary) and adjusted to $\sim 7.0$ adding small aliquots of 0.1 
$\mathrm{M} \mathrm{NaOH}$. FTIR experiments were carried out in $\mathrm{D}_{2} \mathrm{O}$. Although we avoided using buffer compounds, the protonable groups of the peptides at the relatively high concentration assured a stable $\mathrm{pH}$. Aggregates were prepared by two days incubation at $37{ }^{\circ} \mathrm{C}$ in a shaker. Differently from the other peptides, $\mathrm{D} 9 \mathrm{~S}(\mathrm{P})$ became viscous only at low temperature upon storing in refrigerator. For concentration measurements the samples were diluted in $6 \mathrm{M}$ guanidium chloride. Peptide concentration was determined by the absorbance at $280 \mathrm{~nm}$ using an extinction coefficient of $6990 \mathrm{M}^{-1} \cdot \mathrm{cm}^{-1}$.

NMR Spectroscopy. All NMR spectra were acquired on a Bruker DRX700 spectrometer (Bruker Corp., Germany) equipped with $5 \mathrm{~mm}$ triple resonance probe on peptide samples of $\sim 1$ $\mathrm{mM}$ concentration at $6.5<\mathrm{pH}<7.1\left(10 \% \mathrm{D}_{2} \mathrm{O}\right.$ and DSS as the internal proton reference standard set to $0 \mathrm{ppm}$ ) at $288 \mathrm{~K} \cdot{ }^{1} \mathrm{H}-{ }^{1} \mathrm{H}$ TOCSY, ${ }^{1} \mathrm{H}-{ }^{1} \mathrm{H}$ COSY and ${ }^{1} \mathrm{H}-{ }^{1} \mathrm{H}$ NOESY spectra were recorded (65 ms $<$ spinlock time $<80 \mathrm{~ms}$, and $100 \mathrm{~ms}<$ mixing time $<300 \mathrm{~ms}$ ) to assign the chemical shifts. The chemical shift deviations were calculated using published method with random coil values ${ }^{36}$ used in other studies of Trp-cage miniproteins. ${ }^{28,37} \mathrm{CSD}_{\text {cage }}$ was derived from the sum of the absolute CSD values of the following protons: $W^{6} \mathrm{H} \varepsilon 1, \mathrm{~L}^{7} \mathrm{H} \alpha, \mathrm{G}^{11} \mathrm{H} \alpha 2, \mathrm{P}^{12} \mathrm{H} \beta 2, \mathrm{R}^{16} \mathrm{H} \alpha$, $\mathrm{P}^{18} \mathrm{H} \alpha, \mathrm{P}^{18} \mathrm{H} \beta 2, \mathrm{P}^{19} \mathrm{H} \delta 1$ and $\mathrm{P}^{19} \mathrm{H} \delta 2, \mathrm{CSD}_{\text {helix }}$ was derived from the CSDs of $\mathrm{Y}^{3} \mathrm{H} \alpha, \mathrm{Q}^{5} \mathrm{H} \alpha, \mathrm{W}^{6} \mathrm{H} \alpha$ and $\mathrm{K}^{8} \mathrm{H} \alpha$.

Transmission electron microscopy. Samples were diluted 20-fold with water and applied to 300-mesh formvar/carbon-coated copper grids, allowed to adhere for $1 \mathrm{~min}$, and stained for 40 sec with $1 \%$ uranyl acetate. Grids were examined by a JEOL 100 CX II transmission electron microscope (JEOL Ltd., Tokyo, Japan) at an accelerating voltage of $60 \mathrm{kV}$.

Circular dichroism spectroscopy. CD measurements were carried out on a Jasco J-715 spectropolarimeter (Japan Spectroscopic Co., Tokyo, Japan) in Hellma quartz cells of 0.01, 0.1 
(250-190 $\mathrm{nm}$ region) or $1 \mathrm{~mm}$ pathlengths (310-240 $\mathrm{nm}$ region) (Hellma $\mathrm{GmbH}$, Müllheim, Germany) using a Peltier-thermostated cell holder. CD spectra were recorded at a scanning speed of $10 \mathrm{~nm} / \mathrm{min}$ in continuous mode using $1 \mathrm{~nm}$ bandwidth and accumulated 3 times. Monomer samples were spun down at $120000 \times \mathrm{g}$ for 30 min in a TLA-100 ultracentrifuge (Beckman Coulter Inc., Fullerton, California, USA) before measurements to remove any aggregate contamination. The spectrum of the aggregated material was produced as the difference between the spectrum of the total sample and that of its supernatant after 30 min centrifugation at $120000 \times \mathrm{g}$. The experiments were repeated 2-4 times and representative spectra were shown. The secondary structure composition was estimated by the GlobalWorks (Olis Inc., Bogart, GA, USA) software package.

Thioflavin-T (ThT) fluorescence measurements. ThT fluorescence was monitored at $485 \mathrm{~nm}$ with excitation at $445 \mathrm{~nm}$ using a SPEX Fluoromax instrument (Spex Industries Inc., Edison, N.J., USA) as described by Naiki et al. ${ }^{38} 5 \mathrm{~nm}$ excitation and emission slits were used. $5 \mu \mathrm{l}$ aliquots of the protein samples were added to $1 \mathrm{ml}$ assay buffer containing $5 \mu \mathrm{M}$ ThT in $50 \mathrm{mM}$ glycine, $100 \mathrm{mM} \mathrm{NaCl}, \mathrm{pH} 8.5$ at $25^{\circ} \mathrm{C}$, and the fluorescence intensity was recorded with no delay. Measurements were carried out in triplicates. The measured intensities of the different samples were normalized to equal protein concentrations. In the used concentration range the ThT fluorescence intensity was proved to be linear to the protein concentration (data not shown).

Fourier-transform infrared spectroscopy. Infrared spectra of Trp-cage peptides at $\sim 10$ $\mathrm{mg} \cdot \mathrm{ml}^{-1}$ concentration were measured on a Bruker IFS28 FTIR spectrophotometer (Bruker Corp., Germany). $\mathrm{CaF}_{2}$ cell with $100 \mu \mathrm{m}$ pathlength was used in water-jacketed cell holder. Temperature was controlled by a Techne TU 16D thermostat, with the actual temperature measured by a sensor attached directly to the $\mathrm{CaF}_{2}$ cell window. Protein concentration of 5-10 
$\mathrm{mg} / \mathrm{ml}$ was relatively low for FTIR measurements, thus the experiments were carried out in $\mathrm{D}_{2} \mathrm{O}$ to avoid the high absorbance of $\mathrm{H}_{2} \mathrm{O}$ in the amide I region (at around $1650 \mathrm{~cm}^{-1}$ ). pD was defined as $\mathrm{pD}=\mathrm{pD}^{*}+0.4$, where $\mathrm{pD}^{*}$, the $\mathrm{pH}$ meter reading in $\mathrm{D}_{2} \mathrm{O}$, is corrected for the isotope effect. 128 scans were accumulated in the $400-4000 \mathrm{~cm}^{-1}$ region with $1 \mathrm{~cm}^{-1}$ resolution. To avoid the contribution of water vapor peaks to the spectra, the instrument was purged with $\mathrm{N}_{2}$. All spectra were corrected with $\mathrm{D}_{2} \mathrm{O}$ baseline. The HPLC purified and lyophilized peptide samples contained trace amounts of trifluoro-acetic acid (TFA), which resulted a sharp peak at $1672 \mathrm{~cm}^{-1}$ in the IR spectra. This peak was eliminated by the subtraction of a TFA spectrum with appropriate ratio. Monomer samples were spun down at $120000 \times \mathrm{g}, 30 \mathrm{~min}$ in a Beckman TLA100 ultracentrifuge before measurements. The spectrum of the aggregated material was produced as the difference between the spectrum of the total sample and its supernatant after $30 \mathrm{~min}$ centrifugation at $120000 \times \mathrm{g}$.

Model building and molecular dynamics (MD) simulation of polyproline II helix. The collagen triple helix X-ray structure of the $\left[(\text { Pro-Pro-Gly })_{10}\right]_{3}$ peptide $^{39}(1 \mathrm{k} 6 \mathrm{f} . \mathrm{pdb})$ was used as a template structure for modeling a polyproline II helix that is formed as a polymer of D9S(P) molecules. The initial structure of the proline-rich C-terminal part of D9S(P) was built up with all possible Pro-Pro-Gly frames by adjusting the corresponding backbone $\varphi, \psi$ angles to those of the template molecule. The triple helix was constructed from the initial structure using four D9S(P) molecules per chain (12 molecules for the three collagen chain) and applying a shift between the collagen chains for necessary overlap to produce a stable polymer. Because only the C-terminal half of the Trp-cage is compatible with the collagen structure, the N-terminal, "hanging" part needs a space (gap) corresponding to two residues in the collagen chain for the clash-free turning out from the triple helix. Models were refined by the UCSF Chimera program 
package $^{40}$ using an AMBER force field ${ }^{41}$ in vacuum. The obtained model of D9S(P) was used to derive another variant with the phosphate group of Ser9 partially protonated (with a single proton, resulting in a group with net charge of -1$)$, which we will denote as $\mathrm{D} 9 \mathrm{~S}(\mathrm{Pp})$ and the D9S variant. The three different models were subjected to molecular dynamics simulations (MD) as implemented in GROMACS $^{42}$, using the AMBER-ff99SBildn forcefield ${ }^{43}$ using the

parametrization of Steinbrecher et al. ${ }^{44}$ for the phosphate moiety. Systems were solvated by approximately 13000 TIP3P water molecules, the total charge of the system was neutralized and physiological salt concentration set using $\mathrm{Na}^{+}$and $\mathrm{Cl}^{-}$ions. Energy minimization of starting structures was followed by sequential relaxation of constraints on protein atoms in three steps and an additional NVT step (all of 200ps) to stabilize pressure. Trajectories of 40ns NPT simulations at $279 \mathrm{~K}$ and 1 bar were recorded for further analysis (collecting snapshots at every 4ps). The original D9S(P) model and the D9S variant reached a stable conformation in 40ns, while in case of the $\mathrm{D} 9 \mathrm{~S}(\mathrm{Pp})$ model, convergence in the same time span was not certain, so that system was allowed a run time of 80ns, during which, however D9S(Pp) did not evolve further (see Supporting information) - thus the states reached by 40ns could be universally be used for comparison purposes. Clustering of conformations ${ }^{45}$ was carried out based on the backbone conformation of each snapshot using a cutoff of $3.0 \AA$. In figures the mid-structures of the most populated clusters (accounting for at least $95 \%$ of all snapshots of the last 10ns) of three simulations are shown.

\section{RESULTS AND DISCUSSION}

The Trp-cage variants (Fig. 1) were incubated for two days at $37^{\circ} \mathrm{C}$ in a shaker at $2-5 \mathrm{mg} \cdot \mathrm{ml}^{-1}$ concentration resulting in most of the cases viscous, aggregated solutions. Importantly, the 
aggregation occurred at neutral $\mathrm{pH}$ spontaneously with no use of any additives or co-solvents. Tc5b and D9E samples showed large amount of white precipitates. The solution of D9S was opalizing and became viscous, while $13 \mathrm{~S}(\mathrm{P}), 14 \mathrm{~S}(\mathrm{P})$ and $20 \mathrm{~S}(\mathrm{P})$ samples became gel-like and remained fully transparent. Unlike other peptides, D9S(P) became viscous only at low temperature $\left(4^{\circ} \mathrm{C}\right)$ upon storing in refrigerator with the solution remaining transparent.

\section{Trp-cage sequence analysis for amyloidogenicity}

We examined the sequences of the Trp-cage variants for aggregation propensity and amyloidogenicity using most of the available predicting algorithms. The region from residue 2 to 7, as a consensus, was predicted to have amyloidogenic propensity (for the list of the algorithms and results see Fig. S1). In the case of the phosphorylated variants, none of the algorithms were able to handle the Ser(P) side-chain, thus it was replaced with glutamic acid. While the various methods provided different results, there were no significant differences between the Trp-cage variants. The region 2-7 is exactly overlapping with the position of the $\alpha$-helix in the native Trpcage molecule suggesting that a significant unfolding is a prerequisite for conversion to an amyloid structure.

Monomer structures from NMR chemical shift deviation (CSD). The relative stability and secondary structure content of the Trp-cage monomers were compared using the same approach as used in other Trp-cage folding studies ${ }^{28,37}$ CSDcage and CSDhelix values were derived from the observed chemical shifts and the random coil values ${ }^{36}$ to measure the extent of cage and helix formation among the different variants. The values revealed that introduction of the bulky and negatively charged phosphate group on the serine side-chains substantially decrease the overall fold stability; the folded fractions changed from $\sim 90 \%$ to $\sim 40 \%$ (D9S(P) or $13 \mathrm{~S}(\mathrm{P})$ or even further to $\sim 5-10 \%(14 \mathrm{~S}(\mathrm{P})$ or $20 \mathrm{~S}(\mathrm{P}))$ indicating that at position 9 and 13 the serine 
phosphorylation is moderately tolerated while at position 14 and 20 it is more destabilizing (Table 1). In Trp-cage, the side-chains of Ser13 and Ser20 are completely solvent exposed while Ser14 is buried and it forms $\mathrm{H}$-bond with the salt-bridging residues ${ }^{28,30}$, therefore the mutation of Ser13 and Ser20 should be less destabilizing than the mutation of Ser14. Interestingly, 20S(P) was even less stable than $14 \mathrm{~S}(\mathrm{P})$ which indicates that the steric hindrance and the electrostatic repulsion between Tyr3 side-chain and the phosphoserine group at position 20 undermine the structure of Trp-cage. At position 9 the phosphoserine moiety is somewhat tolerated since it does not differ substantially in size and charge from aspartate, therefore the CSDcage and CSDhelix values are the highest here among the studied variants. Moreover, in the spectra of D9S(P) and 13S(P) we observed one and three additional minor conformers, respectively which displayed somewhat different overall structures. However, due to heavy peakoverlaps only partial assignment was achievable for the minor forms. No sign of minor conformers were detected in the spectra of $14 \mathrm{~S}(\mathrm{P})$ or $20 \mathrm{~S}(\mathrm{P})$.

Table 1. Residual folding and $\alpha$-helix propensities of the four Tc5b_x $\mathrm{S}(\mathrm{P})$ derivatives at $288 \mathrm{~K}$.

\begin{tabular}{cccccc}
\hline Peptide & CSD $_{\text {cage }}(\mathbf{p p m})^{a}$ & CSD $_{\text {helix }}(\mathbf{p p m})^{a}$ & $\chi_{\text {cage }^{b}}$ & $\chi_{\text {helix }^{b}}$ & $\begin{array}{c}\boldsymbol{\alpha} \text {-helix } \\
\mathbf{( \% )}^{d}\end{array}$ \\
\hline Tc5b & $10.17^{a}$ & $1.76^{a}$ & 0.89 & 0.86 & $35^{c}$ \\
Tc5b_D9S(P & 1.63 & 1.16 & 0.44 & 0.45 & 23 \\
$\begin{array}{c}\text { Tc5b_13S(P) } \\
\text { Tc5b_14S(P) }\end{array}$ & 4.07 & 0.99 & 0.36 & 0.34 & 20 \\
Tc5b_20S(P) & 0.76 & 0.63 & 0.05 & 0.18 & 12 \\
\hline
\end{tabular}

\footnotetext{
${ }^{a}$ Cumulative chemical shifts of selected resonances (for details see Table S2) to characterize both the Trp-cage fold and the $\alpha$-helical secondary structural element. ${ }^{b}$ Cage and helix fractions. ${ }^{c}$ Unfolded reference and ${ }^{d}$ overall $\alpha$-helix percentages.
} 
Secondary structure studied by CD spectroscopy. Figure 2A shows the representative CD spectra of the monomers and aggregated forms of different Trp-cage variants. Monomer, native form of D9E and D9S mutants show helical structure, as reported previously. ${ }^{26,29,30}$ All the phosphorylated mutant monomers proved to be disordered exhibiting spectra similar to that of D9E at $60{ }^{\circ} \mathrm{C}$ (Fig. 2A and Fig. S2). The spectra of the aggregated D9E, D9S and 13S(P) variants suggest dominantly $\beta$-sheet structures (Fig. 2A) and are similar to those reported for amyloid fibrils. ${ }^{46-49}$ In case of D9E, the amplitude is relatively low which might be explained by the presence of significant amount of precipitated material with large aggregate particles. Some precipitates were also observed in the D9S aggregated sample, while aggregated $13 \mathrm{~S}(\mathrm{P})$ was fully transparent showing a spectrum typical of amyloid fibrils.

A

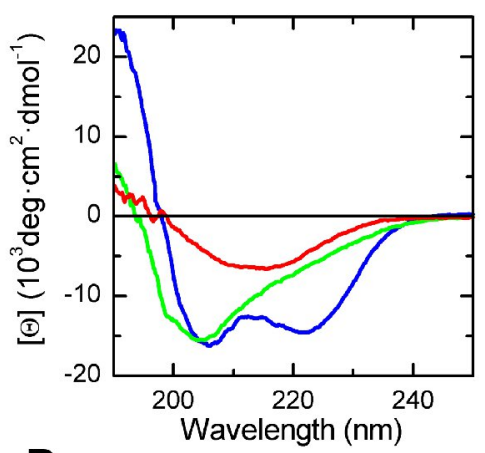

B

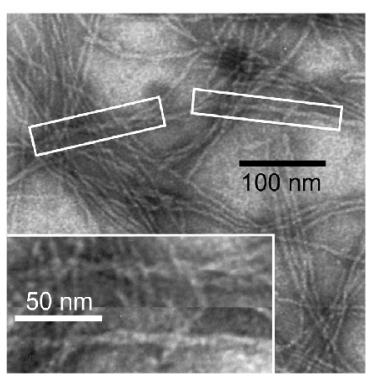

D9S
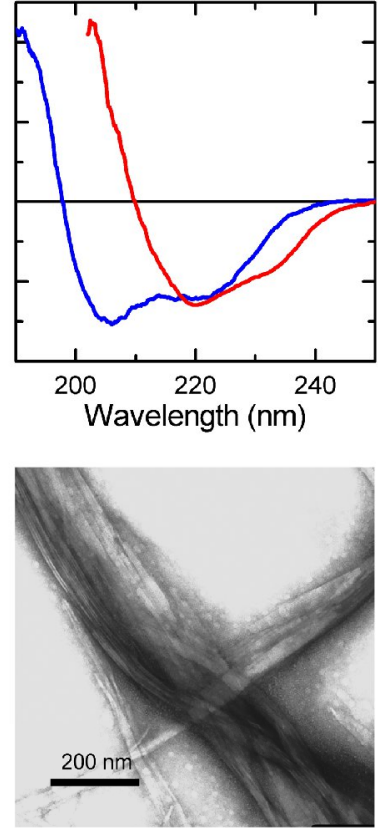

D9S(P)
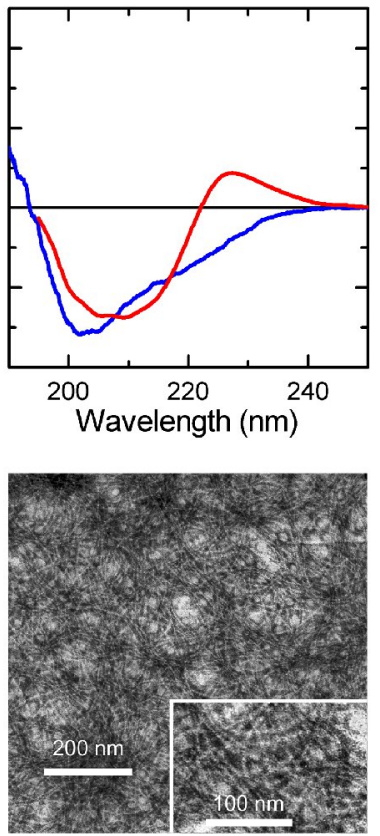

13S(P)
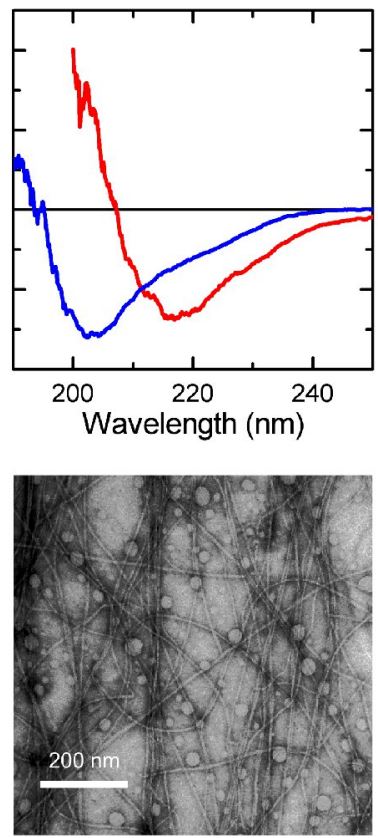

Figure 2. CD spectra and TEM images of the Trp-cage aggregates. (A) CD spectra of the monomer (-) and aggregated Trp-cage variants (-) at $9{ }^{\circ} \mathrm{C}$. The aggregated materials were prepared by two days incubation at 37 ${ }^{\circ} \mathrm{C}$, except that of D9S(P), which was incubated at $4{ }^{\circ} \mathrm{C}$. For D9E, a disordered spectrum recorded at $60{ }^{\circ} \mathrm{C}$ is also presented (-). (B) TEM images of the fibrillar aggregates of Trp-cage variants. In case of D9E, white boxes indicate associated fibrils exhibiting clear helical twist and are enlarged at the bottom. 
D9S(P) showed only a minor fraction of aggregated material after incubation at $37{ }^{\circ} \mathrm{C}$ (Fig. S3). However, differently from the other Trp-cage variants, it formed significant amount of aggregated material after incubation in the refrigerator at $4^{\circ} \mathrm{C}$. Intriguingly, its $\mathrm{CD}$ spectrum was different from all others, exhibiting an unusual profile with a positive maximum at $227 \mathrm{~nm}$ and a minimum at around $208 \mathrm{~nm}$. This spectrum resembles to the spectra of polyproline II helices, proline-rich peptides, or left-handed triple helices of collagen. ${ }^{50,51}$ This finding is further supported by the fact that the C-terminal half of the Trp-cage is rich in proline residues. Although this PPII-type spectrum can be found even in the monomer state of proline-rich peptides, it is important to note that in the case of $\mathrm{D} 9 \mathrm{~S}(\mathrm{P})$, it was the polymerized material which exhibited this unique spectral profile raising the probability that matured triple helix is formed.

\section{Morphology of the Trp-cage aggregates studied by transmission electron microscopy.}

TEM images displayed long, unbranched fibrils with variety in length, diameter and morphology

(Fig. 2B). In the case of D9E, some thin fibrils with diameter of $2.3 \pm 0.3 \mathrm{~nm}$ were observed which might represent single individual protofilaments. Main portion of the fibrils exhibited an average diameter of $4.4 \pm 0.3 \mathrm{~nm}$ probably consisting of two protofilaments. We could also see thick fibrils of complex morphology consisting of several protofilaments exhibiting clear helical twist with a periodicity of $30-35 \mathrm{~nm}$ as highlighted by white rectangles in the panel of D9E in Figure 2B. D9S fibrils formed bundles as thick as 100-200 nm. This lateral association of fibrils

might be explained by the absence of the charge on the $9^{\text {th }}$ side chain, which can otherwise have a repulsive electrostatic effect. 13S(P) formed long, straight, individual fibrils typical of amyloid fibrils. In the case of D9S(P), the appearance of the aggregates were different from all the others: we observed long, thin $(2.5 \pm 0.3 \mathrm{~nm})$ and curved fibrils which did not form any bundles. 
Amyloid specific thioflavin-T fluorescence. The formation of amyloid-like aggregates of Trp-cage variants was verified by the amyloid specific fluorescent dye, thioflavin-T (ThT) ${ }^{38}$ Monomer samples showed no ThT fluorescence. The aggregated samples showed high ThT fluorescence intensity indicating the presence of amyloid conformation with the exception of the D9S(P) variant (Fig. 3). D9S(P), after incubation at $37^{\circ} \mathrm{C}$, showed marginal ThT fluorescence intensity with low amount of aggregated material indicating that the phosphorylation of Ser9 is unfavorable for amyloid formation. After incubation at $4{ }^{\circ} \mathrm{C}$, we observed a large amount of aggregated material, however, with still negligible ThT fluorescence intensity (Fig. 3). This suggests that the structure of the majority of $\mathrm{D} 9 \mathrm{~S}(\mathrm{P})$ aggregates is non-amyloid.



Fig. 3. ThT fluorescence intensity of the aggregated Trp-cage variants. All aggregated samples showed high ThT fluorescence intensity indicating the presence of amyloid conformation except that of D9S(P).

Structural comparison by FTIR spectroscopy. The secondary structure content of the monomer and aggregated Trp-cage variants was further studied by FTIR spectroscopy, which is a suitable technique for investigating opalizing and precipitated samples. The amide-I vibrational band (1600-1700 $\mathrm{cm}^{-1}$ ), dominated by the CO stretching of the peptide bond, is sensitive to the secondary structure of the polypeptide chain. IR spectra of the Tc5b, D9E, and D9S monomers showed spectral features characteristic of a helical structure with the main component around 
1643-1645 $\mathrm{cm}^{-1}$. The monomer forms of phosphorylated D9S(P), 13S(P), 14S(P) and 20S(P) variants exhibited disordered structures with spectral maximum at $\sim 1640 \mathrm{~cm}^{-1}$ (Fig. 4A). IR spectra of the different aggregated forms displayed spectral components significantly different from that of the monomers, exhibiting sharp bands at lower wavenumbers (Fig. 4B). After two days incubation at $37^{\circ} \mathrm{C}$, the aggregates of Tc5b, and the variants D9E, D9S, $13 \mathrm{~S}(\mathrm{P}), 14 \mathrm{~S}(\mathrm{P})$ and 20S(P) exhibited amide-I bands at 1613 and $1624 \mathrm{~cm}^{-1}$ indicative of the presence of intermolecular $\beta$-sheet structure (Fig. 4B). ${ }^{52-55}$ D9S(P) aggregates showed two sharp peaks at 1613 and $1629 \mathrm{~cm}^{-1}$ with a broader shoulder around $1650 \mathrm{~cm}^{-1}$ with ratios different from that of the peaks of the other two-days aggregates suggesting the presence of a different secondary structure (Fig. 4B, C). Bryan et al. carried out FTIR measurements and simulations on collagen model peptides such as (Pro-Pro-Gly/Ala) $)_{10}$ and assigned the component at $1629 \mathrm{~cm}^{-1}$ mainly to vibrations of the amide carbonyls located between two prolines in a triple helical conformation. ${ }^{56}$ Although D9S(P) has a more diverse amino acid composition than the simple Pro-Pro-X model peptides, the $1629 \mathrm{~cm}^{-1}$ peak is clearly manifested.

Intriguingly, we could observe the maturation of the $13 \mathrm{~S}(\mathrm{P})$ and $14 \mathrm{~S}(\mathrm{P})$ aggregates in the FTIR experiments. After dissolving these two peptides, the spectra of their early aggregates were found to be different from those of the samples incubated for two days at $37{ }^{\circ} \mathrm{C}$ and, rather, they reminded of the spectrum of $\mathrm{D} 9 \mathrm{~S}(\mathrm{P})$ aggregates in the position and ratio of the components (Fig. 4C). This observation suggests that at high peptide concentration $\left(\sim 10 \mathrm{mg} \cdot \mathrm{ml}^{-1}\right)$, a fast forming intermediate polymer emerges, which is converted to amyloid fibrils on a longer time-scale. This conversion is not observed for $\mathrm{D} 9 \mathrm{~S}(\mathrm{P})$, where the phosphorylation of Ser9 traps the conformation in the "early" state. 

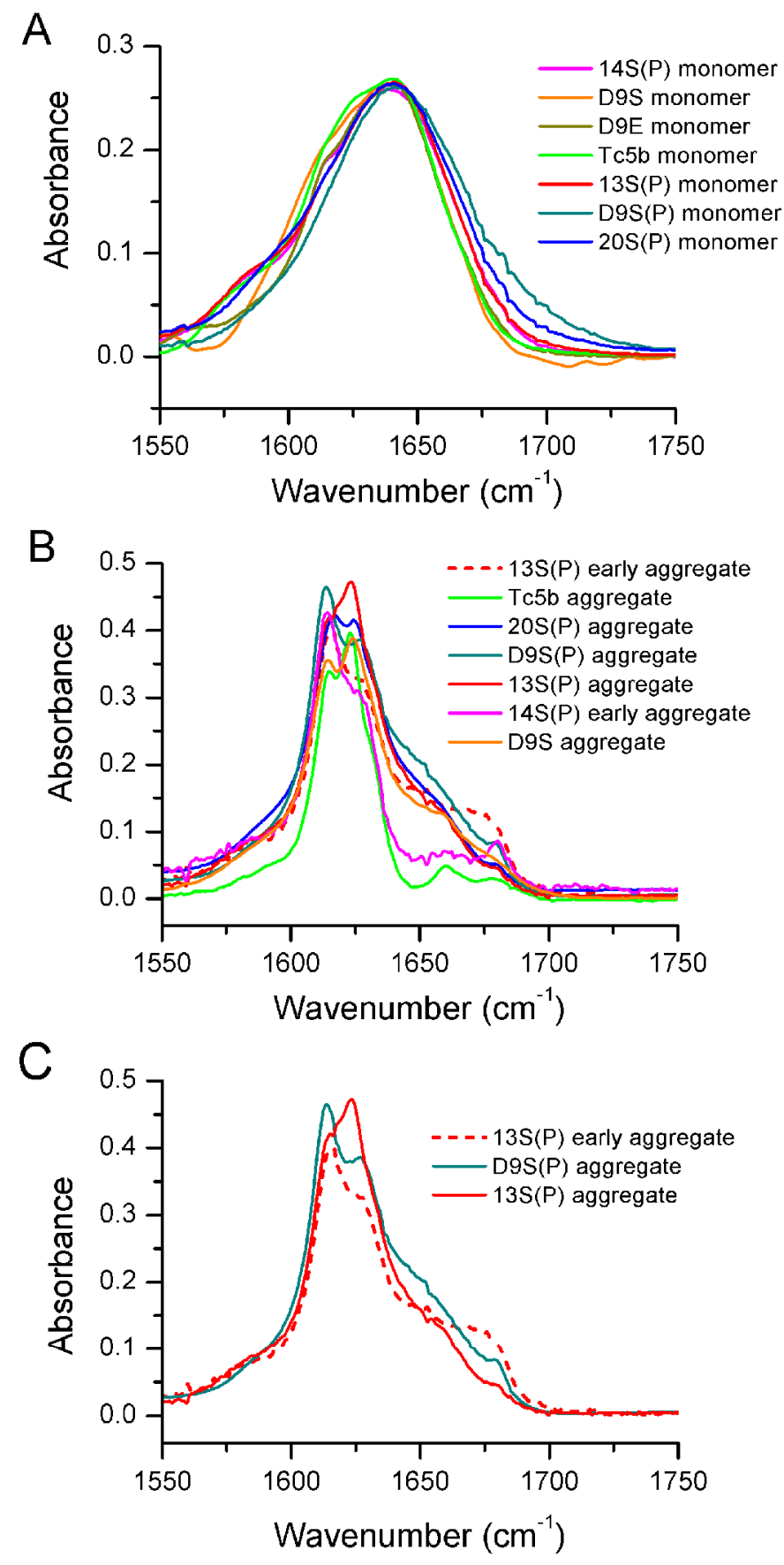

Figure 4. FTIR detected amide-I vibrational bands of Trp-cage variants. (A) IR spectra of monomers show spectral features of either helical (1643-1645 $\left.\mathrm{cm}^{-1}\right)$ and/or disordered $\left(\sim 1640 \mathrm{~cm}^{-1}\right)$ structures. (B) Unlike D9S(P), IR spectra of the different aggregated forms have typically two sharp bands $\left(1613 \mathrm{~cm}^{-1}\right.$ and $1624 \mathrm{~cm}^{-1}$ ), attributed to $\beta$-strands. The aggregate of D9S(P) exhibits amide-I bands at 1613 and $1629 \mathrm{~cm}^{-1}$. (C) Maturation of 13S(P) amyloid fibrils in "two-steps": after dissolving $13 \mathrm{~S}(\mathrm{P})$, the spectrum of an "early" aggregate reminds to that of $\mathrm{D} 9 \mathrm{~S}(\mathrm{P})$ aggregates and is different from the one recorded after two days incubation.

\section{D9S(P) and early aggregates of 13S(P) and 14S(P) exhibit PPII helix structure. Compared}

to the aggregates of other Trp-cage variants, D9S(P) exhibited some unique features. It formed thin flexible fibrils with negligible ThT binding capacity. Moreover, its CD spectrum was reminiscent of a polyproline II helix and FTIR also pointed out clear structural differences. 
Taking into account that the C-terminal half of the protein is rich in Pro residues (Fig. 1), these results suggest that $\mathrm{D} 9 \mathrm{~S}(\mathrm{P})$ forms a collagen-like PPII structure instead of the cross- $\beta$-sheet of amyloid fibrils. To verify the feasibility of this hypothesis we have built a PPII triple helical polymer model for this peptide. The collagen triple helix X-ray structure of the [(Pro-ProGly $\left.)_{10}\right]_{3}$ peptide (1k6f.pdb) served as a template. We have tried to assemble all possible filament constructions. Only one solution resulted in extended H-bonded architecture with no steric clashes while all other arrangements showed either severe steric clashes or the lack of essential stabilizing interactions. In the lowest energy solution, every chain of the polyproline triple helix model is built from the repetitive unit containing the $\mathrm{C}$-terminal ten residues of the peptide in a PPII conformation and a two-residue space (gap) for the clash-free turning out of the N-terminal part from the collagen chain. This results in a 12 residue long periodicity within the nanostructure. A shift of 4 residues between the collagen chains was applied to reach sufficient and symmetrical overlap between the monomers to provide a stable H-bonded polymer. In this model, $70 \%$ of the H-bonds of a collagen triple helix are formed. It is intriguing how the $\mathrm{C}$ terminal half of Trp-cage can adopt the triple helix conformation. The 12 residues PPGPPGPPGPPG repeat of ideal collagen sequence is replaced by the --GPSSGRPPPS sequence starting with the two vacancies that is necessary for the turning out $\mathrm{N}$-terminal part of the molecule and followed by the $\mathrm{Gly}^{11}-\mathrm{Ser}^{20} \mathrm{C}$-terminal half of Trp-cage. 8 positions are identical or fully compatible with the ideal sequence. The bulkier side chains at the remaining four positions are all compensated by a vacancy on the neighboring collagen chain or pointing outwards, such as $\operatorname{Arg} 16$ in the position of a proline. In addition, intermolecular $\operatorname{Arg}^{16}-\operatorname{Ser}(\mathrm{P})^{9}$ salt-bridges arose between the collagen chains which might be a key event in oligomer stabilization (Fig. 5). The distance between the Arg and Ser(P) groups is 2.6-2.7 $\AA$ indicating a 
strong interaction. Besides providing stability, such specific interactions lock the register of "sticky-ends" and enable the self-assembly of these shorter peptides to longer triple-helical fibers. The diameter of the triple helix is consistent with that of the D9S(P) filaments observed by TEM. We have to note that $\mathrm{D} 9 \mathrm{~S}(\mathrm{P})$ fibrils are stable at low temperature. The replacement of the prolines in the collagen consensus sequence with other natural amino acids usually results in significant destabilization.

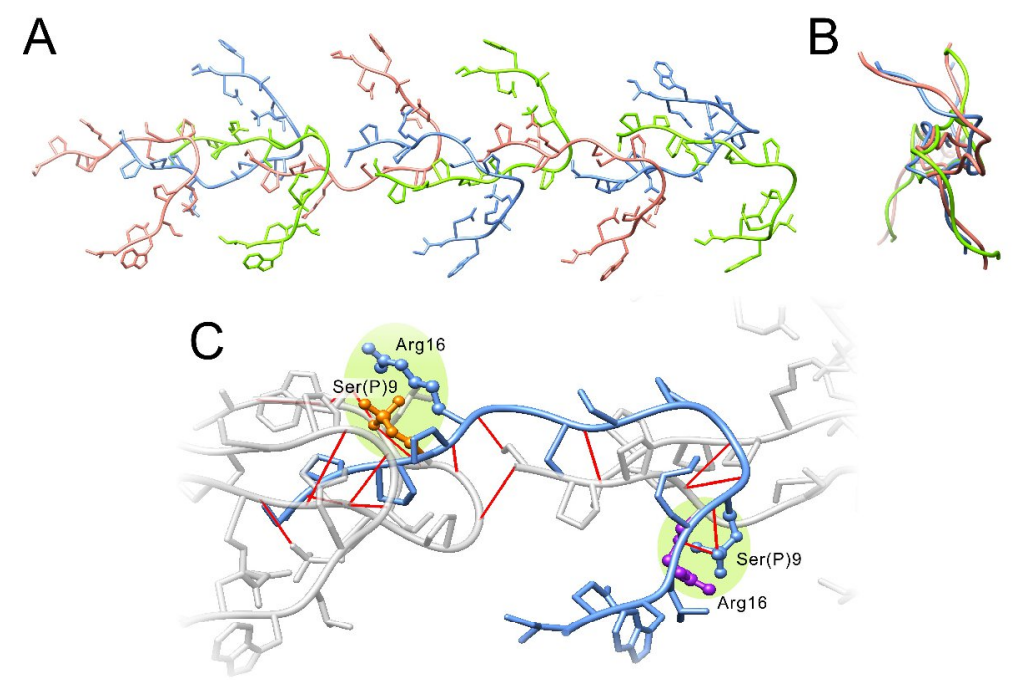

Figure 5. Starting model of $\mathrm{D} 9 \mathrm{~S}(\mathrm{P})$ filaments. Residues $4-20$ of each molecules are shown. (A) A fragment of the PPII triple-helix fibril; red, green and blue stand for the three chains forming collagenlike structure. (B) View of the triple helix from its main axis. (C) A monomer subunit and its interactions in the triple helix. H-bond pattern is depicted by red. The side chains forming $\operatorname{Arg}^{16}-\operatorname{Ser}(\mathrm{P})^{9}$ salt bridges are presented with ball and stick.

MD simulations were carried out to ascertain the stability of the created model, and to test the effect of partial protonation of the Ser9-phosphate (as a model of shifting the $\mathrm{pH}$ to lower values) and its complete removal. Since a self-repeating unit that could be used (with periodic boundary conditions) to create an infinite fibril would be a 48 -mer of the 20 amino acid-long monomer units, the simulation of which is out of the scope of this work, a 12-mer model was considered on 
its own instead. This model, however, lacks the stabilization that would arise from forming a long-range ordered structure. Nevertheless, the overall topology of the model created by us was upheld in the low temperature MD simulations. As it can be seen both in the structure obtained from the calculation (Fig. 6A) and the observed decrease of the radii of gyration (Fig. 6B), protonation of the S9-phosphate group (D9S(Pp)) or its removal (D9S) resulted in the destabilization of the fibril-like structure. The number of the $\operatorname{Arg}^{16}-\operatorname{Ser}(\mathrm{P})^{9} \mathrm{H}$-bonds decreased accordingly - of the 11 possible such linkers along the 12-mer of the calculations - $8 \operatorname{Arg}^{16}$ $\operatorname{Ser}(\mathrm{P})^{9}$ H-bonds were found in snapshots of D9S(P), while 3-5 in case of D9S(Pp) (with an average value of $4.5 \pm 0.5$ ) and $0-2$ in case of D9S (with an average value of $0.2 \pm 0.4$ ).


Figure 6. MD simulations on the collagen triple helix model. (A) Structures of D9S(P), the partially protonated D9S(Pp), and D9S triple helices after MD simulation. (B) The change of the radii of gyration during MD simulation, and (C) rmsd compared to the starting model. The simulation for D9S(Pp) was extended with another 40 nsec, which part is presented by shifting back to the $0-40 \mathrm{nsec}$ range (magenta). 
In line with our findings, charge pairing between aspartates and lysines of adjacent chains lead to high stability triple helix formation in heterotrimers of highly substituted short peptide sequences. ${ }^{57}$ Long, collagen-like fibers of short model peptides have been described by Kotch and coworkers in which the three strands are held in a staggered array by disulfide bonds. ${ }^{58}$

\section{pH dependence of the aggregation of D9S(P) and 13S(P) Trp-cage variants}

Investigation of the $\mathrm{pH}$ dependence of the aggregation provided an opportunity to test the $\operatorname{Arg}^{16}-\operatorname{Ser}(\mathrm{P})^{9}$ charge pair suggested by the triple helix model of D9S(P). Phosphoserine sidechains have one $\mathrm{pKa}$ value around 2 and a second $\mathrm{pKa}$ around 6 when they lose a second proton. ${ }^{59}$ At $\mathrm{pH} 7$ used in our study, the phosphorylated side-chains are double negative. At lower $\mathrm{pH}$, such as 4, the $\mathrm{D} 9 \mathrm{~S}(\mathrm{P})$ variant has charges that are similar to that of the normal Trpcage, $\mathrm{Tc} 5 \mathrm{~b}$, at $\mathrm{pH} 7$, with a single negative charge on the 9th side-chain. We compared the aggregation properties of $\mathrm{D} 9 \mathrm{~S}(\mathrm{P})$ and the amyloid forming $13 \mathrm{~S}(\mathrm{P})$ variant at $\mathrm{pH} 4$ and $\mathrm{pH} 7$. We measured the thioflavin-T fluorescence, the far-UV CD spectra and determined the amount of the aggregated material by ultracentrifugation. $13 \mathrm{~S}(\mathrm{P})$ variant showed amyloidogenicity at both $\mathrm{pHs}$ with high thiflavin-T fluorescence intensity and significant amount of aggregated material. At $\mathrm{pH} 4$, the strongly aggregating $13 \mathrm{~S}(\mathrm{P})$ fibrils precipitated out of the solution which made the correct $\mathrm{CD}$ measurements impossible, while at $\mathrm{pH} 7$, the characteristic $\beta$-sheet like $\mathrm{CD}$ spectrum was manifested (Fig. S4). In contrast, D9S(P) at pH 4 did not show any sign of aggregation when incubated either at $37^{\circ} \mathrm{C}$ or at low temperature for a week. The ultracentrifugation experiment showed no spinnable material and the CD spectrum has not changed at the least. In the case of D9S(P) at $\mathrm{pH} 7, \mathrm{CD}$ spectra indicated the presence of the characteristic PPII state with high amount of polymerized material and low thioflavin-T binding affinity (Fig. S4). The observed 
pH sensitivity of D9S(P) aggregation is consistent with the likely loss of the $\operatorname{Arg}^{16}-\operatorname{Ser}(\mathrm{P})^{9}$ salt bridge at $\mathrm{pH} 4$. At $\mathrm{pH} 4$, where the charges of the molecule are similar to that of the native Trpcage $(\mathrm{Tc} 5 \mathrm{~b})$ at $\mathrm{pH} 7$, we could expect the amyloid formation of D9S(P). However, this is not the case, which suggests that the bulky phosphate group at position 9 destabilizes the amyloid form. Indeed, it is very close to the hypothetic end of the $\beta$-strands (at residues 7 or 8 ) in the amyloid fibrils predicted from the sequence by various methods (Fig. S1).

To further verify that $9 \mathrm{~S}(\mathrm{P})$ forms unique polymer structure, we also measured and compared the near-UV CD spectra of different forms of $9 \mathrm{~S}(\mathrm{P}), 13 \mathrm{~S}(\mathrm{P})$, and the native, $\alpha$-helical Trp-cage. Although we cannot infer site specific structural information from the near-UV CD of the aromatic side-chains, it is sensitive to any conformational changes and works as a fingerprint. The near-UV CD spectrum of 9S(P) aggregates were different from that of all other monomer and amyloid forms (Fig. S5).

Trp-cage conformations and aggregation mechanism. Today, protein folding research is also focusing on protein misfolding and aggregation due to its disease-related importance. ${ }^{60}$ In the present work, we show that Trp-cage miniproteins are capable of forming different aggregates including amyloid fibrils at physiological $\mathrm{pH}$ at elevated concentrations. However, this concentration is similar to that reported to be essential for amyloid formation of the GNNQQNY core segment of yeast prion Sup35. ${ }^{61}$ Using different mutants and phosphorylated serine variants, we gained site-specific information on the structure of the different forms of Trpcage and we could outline the aggregation mechanism. The CD and NMR results revealed that the phosphorylation of any of the serine residues destabilizes the native structure leading to a highly dynamic disordered chain (Table 1 and Fig. 2). The effect of phosphorylation is often 
mimicked in molecular biology with aspartate or glutamate residues as substitutes. However, this is not applicable here, as D9E has a stable native like 3D structure ${ }^{29}$, while in its pair, D9S(P), a loss of the $\alpha$-helical structure is observed. Analyses of CD and FTIR data revealed that the structure of any of the aggregated forms of Trp-cage variants lack $\alpha$-helical conformation indicating that aggregates have strikingly different secondary structures. Thus, aggregation occurs via partial or complete unfolding of the native state. This hypothesis is supported by the fact that the "natively unfolded" $13 \mathrm{~S}(\mathrm{P}), 14 \mathrm{~S}(\mathrm{P})$ and $20 \mathrm{~S}(\mathrm{P})$ variants easily polymerize into amyloid fibrils. On the contrary, D9S(P) fibers exhibit unique, collagen triple-helix-like spectral and structural properties stabilized by intermolecular $\operatorname{Ser}(\mathrm{P})^{9}-\operatorname{Arg}^{16}$ salt bridges. Besides, $\beta$ strand aggregation of peptides and proteins can also occur via collagen-like triple helix multimerization as foreseen by theoretical calculations some years ago. ${ }^{62}$ Intriguingly, we found that early aggregates of $13 \mathrm{~S}(\mathrm{P})$ and $14 \mathrm{~S}(\mathrm{P})$ show infrared spectra similar to that of $\mathrm{D} 9 \mathrm{~S}(\mathrm{P})$ fibers (Fig. 4C) suggesting that collagen/PPII helix might be an intermediate structure on the route of amyloid fibril formation. While the PPII like backbone structure (with $(\varphi, \psi)$ backbone dihedral angles around $\left.\left(-75^{\circ},+145^{\circ}\right)\right)$ of residues $11-20$ was retained in monomers in the low temperature MD simulations of D9S(P), D9S(Pp) and D9S (Fig. S6), the collagen helix-like association of these monomers was only stable in case of D9S(P). Due to its favorable salt-bridge motif and possible steric hindrance in the amyloid state, the $\mathrm{D} 9 \mathrm{~S}(\mathrm{P})$ variant gets trapped in this intermediate, pre-amyloid form. In the absence of such interactions, monomers can progress to forming $\beta$-sheet type aggregates. The role of the collagen-like aggregate state in amyloid formation might be the increase of local concentration promoting further intermolecular interactions such as the structural conversion to amyloid fibrils. Similar phenomenon was observed for Huntingtin, the glutamine-rich protein responsible for Huntington's disease, where 
the N-terminal $\alpha$-helical segment, which otherwise do not interact with the polyQ amyloid fibril core, greatly accelerates aggregation. ${ }^{63}$ Furthermore, as PPII helix is an extended conformation which overlaps with the allowed region of $\beta$-sheet structure $^{64}$, this conformation could be favorable for the conversion of the non-proline residues to the cross- $\beta$-sheet structures of amyloid fibrils. Blanch and co-workers emphasized the role of PPII structure in the conversion of the $\alpha$-helical human lysozyme into amyloid fibrils. ${ }^{65}$ Bielska et al. reported that hyperphosphorylation of tau induces local polyproline II helix. ${ }^{66}$ In our earlier theoretical work, the formation of PPII structure was predicted to be energetically favorable. ${ }^{62}$ The present results give solid experimental evidence that besides intermolecular $\beta$-sheet formation, PPII structurebased aggregation can also take place. Therefore we suggest an aggregation scheme (depicted in Figure 7) which includes all the possible states Trp-cage miniproteins and presumably other globular proteins can visit during their conversion from native to aggregated state.

Recently, investigation of the possible role of phosphorylation in aggregation and amyloidoses of $\alpha$-synuclein, amyloid- $\beta$, superoxide dismutase, prion and other proteins emerged into notice and outlined the host of far-reaching effects, either on molecular or on cellular levels. ${ }^{19-21,25,67-69}$ Our results demonstrated that Trp-cage miniproteins are sensitive models for studying the effect of phosphorylation on aggregation and amyloid formation, exhibiting highly site-specific effects, in some cases facilitating and in others by blocking amyloid fibrillization. 


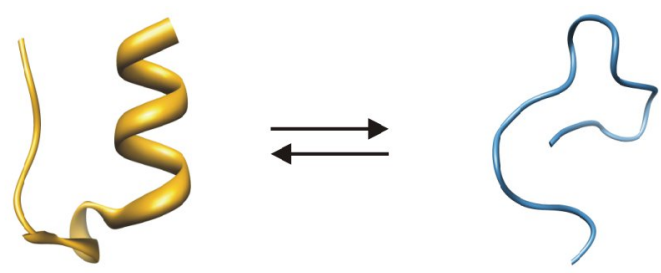

Native state

Unordered state

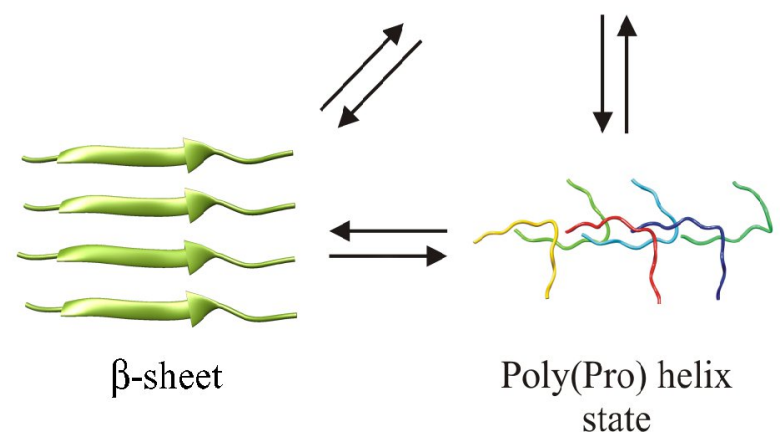

Figure 7. Schematic representation of the different structures and theoretical pathways exhibited by Trpcage miniproteins. The native fold (Tc5b, D9E, D9S) can be destabilized at higher temperature, protein concentration and/or by destabilizing modifications (e.g. phosphorylation), resulting in a dynamic and mostly disordered conformational ensemble. This dynamic form could be converted into a PPII helical polymer, as is the case for $\mathrm{D} 9 \mathrm{~S}(\mathrm{P})$, before reaching the amyloid state. For other model systems $(13 \mathrm{~S}(\mathrm{P})$, $14 \mathrm{~S}(\mathrm{P})$ and $20 \mathrm{~S}(\mathrm{P}))$ the conformational equilibrium is shifted directly towards the most stable amyloid fibrils. Accordingly, all models end in a folding dead-end street as the $\beta$-sheet is the thermodynamically available most stable structural ensemble.

\section{CONCLUSION}

Here, we challenged the stable, $\alpha$-helix dominated fold of Trp-cage by using high protein concentration and applying site-specific modifications: serine phosphorylations. The monomer forms of the phosphorylated variants exhibit mostly disordered structures. With the exception of D9S(P), all aggregated Trp-cage variants show CD spectra of high $\beta$-structure content and amide-I IR bands characteristic of intermolecular $\beta$-sheets. TEM images revealed the presence of highly ordered amyloid-like fibrils of various size and morphology. Their high ThT fluorescence verifies an amyloid-like structure. Intriguingly, D9S(P) forms thin fibrils showing a PPII-helix type CD spectrum with a negligible ThT binding capacity. Inspired by these new experimental 
results and structural restraints, our atomic resolution model of $\mathrm{D} 9 \mathrm{~S}(\mathrm{P})$ aggregate suggests a collagen-like polymer form. In summary, Trp-cage miniproteins adopt characteristic conformational states like larger proteins do: from a globular structure through highly dynamic random coil to ordered amyloid fibrils. The phosphorylation of a single serine residue serves not only as a conformational switch between the ordered and unstructured states, but it also contributes to the fine-tuning of the intermolecular $\beta$-sheet formation via PPII structure-based aggregation. Using the atomic level structural information on Trp-cage folds, one could decipher modes of structural transformation of larger proteins from native to amyloid states.

\section{ASSOCIATED CONTENT}

Supporting Information. Detailed method of Peptide synthesis and purification, analytical properties of Trp-cage variants (Table S1), Sequence analysis for amylidogenic regions of Trpcage (Fig. S1), Chemical shift deviations for representative Trp-cage sequences at $288 \mathrm{~K}$ (Table S2), CD spectra of 14S(P) and 20S(P) (Fig. S2), CD spectra of D9S(P) incubated at $37{ }^{\circ} \mathrm{C}$ (Fig. S3), Comparison of Trp-cage variants at $\mathrm{pH} 4$ and $\mathrm{pH} 7$ by $\mathrm{CD}$ (Fig. S4) and Spectral comparison in near UV CD (Fig. S5), Distribution of backbone dihedral angles after MD simulations (Fig. S6) are presented. This material is available free of charge via the Internet at http://pubs.acs.org.

\section{AUTHOR INFORMATION}

\section{Corresponding Author}

* József Kardos, phone: +36 3722500/1795; e-mail: kardos@elte.hu and/or András Perczel, phone: +36 3722500/1653; e-mail: perczel@chem.elte.hu. 


\section{Notes}

The authors declare no competing financial interest.

\section{ACKNOWLEDGMENT}

J. Kardos is a Bolyai János Researh fellow of the Hungarian Academy of Sciences. This work was supported by the Hungarian Scientific Research Fund (OTKA 81950, NK101072) and TÁMOP-4.2.1.B-09/1/KMR.

\section{ABBREVIATIONS}

ThT, thioflavin-T; TEM, transmission electron microscopy

\section{REFERENCES}

(1) Eakin, C. M.; Berman, A. J.; Miranker, A. D., A Native to Amyloidogenic Transition Regulated by a Backbone Trigger. Nat Struct Mol Biol 2006, 13, 202-208.

(2) Fowler, D. M.; Koulov, A. V.; Balch, W. E.; Kelly, J. W., Functional Amyloid--from Bacteria to Humans. Trends Biochem. Sci. 2007, 32, 217-224.

(3) Hane, F., Are Amyloid Fibrils Molecular Spandrels? FEBS Lett 2013, 587, 3617-3619.

(4) Nelson, R.; Sawaya, M. R.; Balbirnie, M.; Madsen, A. O.; Riekel, C.; Grothe, R.; Eisenberg, D., Structure of the Cross-Beta Spine of Amyloid-Like Fibrils. Nature 2005, 435, 773-778.

(5) Wright, C. F.; Teichmann, S. A.; Clarke, J.; Dobson, C. M., The Importance of Sequence Diversity in the Aggregation and Evolution of Proteins. Nature 2005, 438, 878-881.

(6) Tycko, R., Molecular Structure of Amyloid Fibrils: Insights from Solid-State Nmr. $Q$. Rev. Biophys. 2006, 39, 1-55.

(7) Benilova, I.; Karran, E.; De Strooper, B., The Toxic Abeta Oligomer and Alzheimer's Disease: An Emperor in Need of Clothes. Nat. Neurosci. 2012, 15, 349-357.

(8) Fandrich, M., Oligomeric Intermediates in Amyloid Formation: Structure Determination and Mechanisms of Toxicity. J. Mol. Biol. 2012.

(9) Atwood, C. S.; Martins, R. N.; Smith, M. A.; Perry, G., Senile Plaque Composition and Posttranslational Modification of Amyloid-Beta Peptide and Associated Proteins. Peptides 2002, 23, 1343-1350.

(10) Broncel, M.; Falenski, J. A.; Wagner, S. C.; Hackenberger, C. P.; Koksch, B., How PostTranslational Modifications Influence Amyloid Formation: A Systematic Study of Phosphorylation and Glycosylation in Model Peptides. Chemistry 2010, 16, 7881-7888.

(11) Khodadadi, S.; Riazi, G. H.; Ahmadian, S.; Hoveizi, E.; Karima, O.; Aryapour, H., Effect of N-Homocysteinylation on Physicochemical and Cytotoxic Properties of Amyloid BetaPeptide. FEBS Lett. 2012, 586, 127-131. 
(12) Kummer, M. P.; Hermes, M.; Delekarte, A.; Hammerschmidt, T.; Kumar, S.; Terwel, D.; Walter, J.; Pape, H. C.; Konig, S.; Roeber, S., et al., Nitration of Tyrosine 10 Critically Enhances Amyloid Beta Aggregation and Plaque Formation. Neuron 2011, 71, 833-844.

(13) Chun, W.; Johnson, G. V., The Role of Tau Phosphorylation and Cleavage in Neuronal Cell Death. Front. Biosci. 2007, 12, 733-756.

(14) Beyer, K.; Ariza, A., Alpha-Synuclein Posttranslational Modification and Alternative Splicing as a Trigger for Neurodegeneration. Mol. Neurobiol. 2013, 47, 509-524.

(15) Braithwaite, S. P.; Stock, J. B.; Mouradian, M. M., Alpha-Synuclein Phosphorylation as a Therapeutic Target in Parkinson's Disease. Rev. Neurosci. 2012, 23, 191-198.

(16) Chen, L.; Periquet, M.; Wang, X.; Negro, A.; McLean, P. J.; Hyman, B. T.; Feany, M. B., Tyrosine and Serine Phosphorylation of Alpha-Synuclein Have Opposing Effects on Neurotoxicity and Soluble Oligomer Formation. J. Clin. Invest.2009, 119, 3257-3265.

(17) Fujiwara, H.; Hasegawa, M.; Dohmae, N.; Kawashima, A.; Masliah, E.; Goldberg, M. S.; Shen, J.; Takio, K.; Iwatsubo, T., Alpha-Synuclein Is Phosphorylated in Synucleinopathy Lesions. Nat. Cell. Biol. 2002, 4, 160-164.

(18) Paleologou, K. E.; Oueslati, A.; Shakked, G.; Rospigliosi, C. C.; Kim, H. Y.; Lamberto, G. R.; Fernandez, C. O.; Schmid, A.; Chegini, F.; Gai, W. P., et al., Phosphorylation at S87 Is Enhanced in Synucleinopathies, Inhibits Alpha-Synuclein Oligomerization, and Influences Synuclein-Membrane Interactions. J. Neurosci. 2010, 30, 3184-3198.

(19) Paleologou, K. E.; Schmid, A. W.; Rospigliosi, C. C.; Kim, H. Y.; Lamberto, G. R.; Fredenburg, R. A.; Lansbury, P. T., Jr.; Fernandez, C. O.; Eliezer, D.; Zweckstetter, M., et al., Phosphorylation at Ser-129 but Not the Phosphomimics S129e/D Inhibits the Fibrillation of Alpha-Synuclein. J. Biol. Chem. 2008, 283, 16895-16905.

(20) Sancenon, V.; Lee, S. A.; Patrick, C.; Griffith, J.; Paulino, A.; Outeiro, T. F.; Reggiori, F.; Masliah, E.; Muchowski, P. J., Suppression of Alpha-Synuclein Toxicity and Vesicle Trafficking Defects by Phosphorylation at S129 in Yeast Depends on Genetic Context. Hum. Mol. Genet. 2012, 21, 2432-2449.

(21) Kumar, S.; Rezaei-Ghaleh, N.; Terwel, D.; Thal, D. R.; Richard, M.; Hoch, M.; Mc Donald, J. M.; Wullner, U.; Glebov, K.; Heneka, M. T., et al., Extracellular Phosphorylation of the Amyloid Beta-Peptide Promotes Formation of Toxic Aggregates During the Pathogenesis of Alzheimer's Disease. Embo J. 2011, 30, 2255-2265.

(22) Kumar, S.; Singh, S.; Hinze, D.; Josten, M.; Sahl, H. G.; Siepmann, M.; Walter, J., Phosphorylation of Amyloid-Beta Peptide at Serine 8 Attenuates Its Clearance Via InsulinDegrading and Angiotensin-Converting Enzymes. J. Biol. Chem. 2012, 287, 8641-8651.

(23) Kumar, S.; Walter, J., Phosphorylation of Amyloid Beta (Abeta) Peptides - a Trigger for Formation of Toxic Aggregates in Alzheimer's Disease. Aging (Albany NY) 2011, 3, 803-812.

(24) Milton, N. G., Phosphorylation of Amyloid-Beta at the Serine 26 Residue by Human Cdc2 Kinase. Neuroreport 2001, 12, 3839-3844.

(25) Milton, N. G., Phosphorylated Amyloid-Beta: The Toxic Intermediate in Alzheimer's Disease Neurodegeneration. Subcell. Biochem. 2005, 38, 381-402.

(26) Neidigh, J. W.; Fesinmeyer, R. M.; Andersen, N. H., Designing a 20-Residue Protein. Nat. Struct. Biol. 2002, 9, 425-430.

(27) Rovo, P.; Straner, P.; Lang, A.; Bartha, I.; Huszar, K.; Nyitray, L.; Perczel, A., Structural Insights into the Trp-Cage Folding Intermediate Formation. Chemistry 2013, 19, 2628-2640. 
(28) Barua, B.; Lin, J. C.; Williams, V. D.; Kummler, P.; Neidigh, J. W.; Andersen, N. H., The Trp-Cage: Optimizing the Stability of a Globular Miniprotein. Protein Eng. Des. Sel. 2008, 21, 171-185.

(29) Hudaky, P.; Straner, P.; Farkas, V.; Varadi, G.; Toth, G.; Perczel, A., Cooperation between a Salt Bridge and the Hydrophobic Core Triggers Fold Stabilization in a Trp-Cage Miniprotein. Biochemistry 2008, 47, 1007-1016.

(30) Rovo, P.; Farkas, V.; Hegyi, O.; Szolomajer-Csikos, O.; Toth, G. K.; Perczel, A., Cooperativity Network of Trp-Cage Miniproteins: Probing Salt-Bridges. J. Pept. Sci. 2011, 17, 610-619.

(31) Scian, M.; Lin, J. C.; Le Trong, I.; Makhatadze, G. I.; Stenkamp, R. E.; Andersen, N. H., Crystal and Nmr Structures of a Trp-Cage Mini-Protein Benchmark for Computational Fold Prediction. Proc. Natl. Acad. Sci. USA 2012, 109, 12521-12525.

(32) Farkas, V., Csordás, B., Hegyi, O., Tóth, G. K. and Perczel, A., Foldamer Stability Coupled to Aggregation Propensity of Elongated Trp-Cage Miniproteins. Eur. J. Org. Chem. 2013, 2013, 3513-3522.

(33) Zhou, R., Trp-Cage: Folding Free Energy Landscape in Explicit Water. Proc. Natl. Acad. Sci. USA 2003, 100, 13280-13285.

(34) Juraszek, J.; Bolhuis, P. G., Sampling the Multiple Folding Mechanisms of Trp-Cage in Explicit Solvent. Proc. Natl. Acad. Sci. USA 2006, 103, 15859-15864.

(35) Perich, J. W.; Johns, R. B., Di-Tert-Butyl N,N-Diethylphosphoramidite and Dibenzyl N,N-Diethylphosphoramidite - Highly Reactive Reagents for the Phosphite-Triester Phosphorylation of Serine-Containing Peptides. Tetrahedron Letters 1988, 29, 2369-2372.

(36) Fesinmeyer, R. M.; Hudson, F. M.; Andersen, N. H., Enhanced Hairpin Stability through Loop Design: The Case of the Protein G B1 Domain Hairpin. J. Am. Chem. Soc. 2004, 126, 7238-7243.

(37) Rovo, P.; Farkas, V.; Straner, P.; Szabo, M.; Jermendy, A.; Hegyi, O.; Toth, G. K.; Perczel, A., Rational Design of Alpha-Helix-Stabilized Exendin-4 Analogues. Biochemistry 2014, 53, 3540-3552.

(38) Naiki, H.; Higuchi, K.; Hosokawa, M.; Takeda, T., Fluorometric Determination of Amyloid Fibrils in Vitro Using the Fluorescent Dye, Thioflavin T1. Anal. Biochem. 1989, 177, 244-249.

(39) Berisio, R.; Vitagliano, L.; Mazzarella, L.; Zagari, A., Crystal Structure of the Collagen Triple Helix Model [(Pro-Pro-Gly)(10)](3). Protein Sci. 2002, 11, 262-270.

(40) Pettersen, E. F.; Goddard, T. D.; Huang, C. C.; Couch, G. S.; Greenblatt, D. M.; Meng, E. C.; Ferrin, T. E., Ucsf Chimera--a Visualization System for Exploratory Research and Analysis. J. Comput. Chem. 2004, 25, 1605-1612.

(41) Cornell, W. D.; Cieplak, P.; Bayly, C. I.; Gould, I. R.; Merz, K. M.; Ferguson, D. M.; Spellmeyer, D. C.; Fox, T.; Caldwell, J. W.; Kollman, P. A., A Second Generation Force Field for the Simulation of Proteins, Nucleic Acids, and Organic Molecules. J. Am. Chem. Soc. 1995, $117,5179$.

(42) Pronk, S.; Pall, S.; Schulz, R.; Larsson, P.; Bjelkmar, P.; Apostolov, R.; Shirts, M. R.; Smith, J. C.; Kasson, P. M.; van der Spoel, D., et al., Gromacs 4.5: A High-Throughput and Highly Parallel Open Source Molecular Simulation Toolkit. Bioinformatics 2013, 29, 845-854.

(43) Lindorff-Larsen, K.; Piana, S.; Palmo, K.; Maragakis, P.; Klepeis, J. L.; Dror, R. O.; Shaw, D. E., Improved Side-Chain Torsion Potentials for the Amber Ff99sb Protein Force Field. Proteins 2010, 78, 1950-1958. 
(44) Steinbrecher, T.; Latzer, J.; Case, D. A., Revised Amber Parameters for Bioorganic Phosphates. J. Chem. Theory Comput. 2012, 8, 4405-4412.

(45) Daura, X.; Antes, I.; van Gunsteren, W. F.; Thiel, W.; Mark, A. E., The Effect of Motional Averaging on the Calculation of Nmr-Derived Structural Properties. Proteins 1999, 36, 542-555.

(46) Kardos, J.; Micsonai, A.; Pal-Gabor, H.; Petrik, E.; Graf, L.; Kovacs, J.; Lee, Y. H.; Naiki, H.; Goto, Y., Reversible Heat-Induced Dissociation of Beta2-Microglobulin Amyloid Fibrils. Biochemistry 2011, 50, 3211-3220.

(47) Kardos, J.; Okuno, D.; Kawai, T.; Hagihara, Y.; Yumoto, N.; Kitagawa, T.; Zavodszky, P.; Naiki, H.; Goto, Y., Structural Studies Reveal That the Diverse Morphology of Beta(2)Microglobulin Aggregates Is a Reflection of Different Molecular Architectures. Biochim. Biophys. Acta 2005, 1753, 108-120.

(48) Pal-Gabor, H.; Gombos, L.; Micsonai, A.; Kovacs, E.; Petrik, E.; Kovacs, J.; Graf, L.; Fidy, J.; Naiki, H.; Goto, Y., et al., Mechanism of Lysophosphatidic Acid-Induced Amyloid Fibril Formation of Beta(2)-Microglobulin in Vitro under Physiological Conditions. Biochemistry 2009, 48, 5689-5699.

(49) Chiti, F.; Webster, P.; Taddei, N.; Clark, A.; Stefani, M.; Ramponi, G.; Dobson, C. M., Designing Conditions for in Vitro Formation of Amyloid Protofilaments and Fibrils. Proc. Natl. Acad. Sci. USA 1999, 96, 3590-3594.

(50) Jenness, D. D.; Sprecher, C.; Johnson, W. C., Jr., Circular Dichroism of Collagen, Gelatin, and Poly(Proline) Ii in the Vacuum Ultraviolet. Biopolymers 1976, 15, 513-521.

(51) Kelly, M. A.; Chellgren, B. W.; Rucker, A. L.; Troutman, J. M.; Fried, M. G.; Miller, A. F.; Creamer, T. P., Host-Guest Study of Left-Handed Polyproline Ii Helix Formation. Biochemistry 2001, 40, 14376-14383.

(52) Jackson, M.; Mantsch, H. H., The Use and Misuse of Ftir Spectroscopy in the Determination of Protein Structure. Crit. Rev. Biochem. Mol. Biol. 1995, 30, 95-120.

(53) Byler, D. M.; Susi, H., Examination of the Secondary Structure of Proteins by Deconvolved Ftir Spectra. Biopolymers 1986, 25, 469-487.

(54) Narhi, L.; Wood, S. J.; Steavenson, S.; Jiang, Y.; Wu, G. M.; Anafi, D.; Kaufman, S. A.; Martin, F.; Sitney, K.; Denis, P., et al., Both Familial Parkinson's Disease Mutations Accelerate Alpha-Synuclein Aggregation. J. Biol. Chem. 1999, 274, 9843-9846.

(55) Krimm, S.; Bandekar, J., Vibrational Spectroscopy and Conformation of Peptides, Polypeptides, and Proteins. Adv. Protein Chem. 1986, 38, 181-364.

(56) Bryan, M. A.; Brauner, J. W.; Anderle, G.; Flach, C. R.; Brodsky, B.; Mendelsohn, R., Ftir Studies of Collagen Model Peptides: Complementary Experimental and Simulation Approaches to Conformation and Unfolding. J. Am. Chem. Soc. 2007, 129, 7877-7884.

(57) Gauba, V.; Hartgerink, J. D., Surprisingly High Stability of Collagen Abc Heterotrimer: Evaluation of Side Chain Charge Pairs. J. Am. Chem. Soc. 2007, 129, 15034-15041.

(58) Kotch, F. W.; Raines, R. T., Self-Assembly of Synthetic Collagen Triple Helices. Proc. Natl. Acad. Sci. USA 2006, 103, 3028-3033.

(59) Bienkiewicz, E. A.; Lumb, K. J., Random-Coil Chemical Shifts of Phosphorylated Amino Acids. J. Biomol. NMR. 1999, 15, 203-206.

(60) Chiti, F.; Dobson, C. M., Protein Misfolding, Functional Amyloid, and Human Disease. Annu. Rev. Biochem. 2006, 75, 333-366. 
(61) van der Wel, P. C.; Lewandowski, J. R.; Griffin, R. G., Solid-State Nmr Study of Amyloid Nanocrystals and Fibrils Formed by the Peptide Gnnqqny from Yeast Prion Protein Sup35p. J. Am. Chem. Soc. 2007, 129, 5117-5130.

(62) Perczel, A.; Hudaky, P.; Palfi, V. K., Dead-End Street of Protein Folding: Thermodynamic Rationale of Amyloid Fibril Formation. J. Am. Chem. Soc. 2007, 129, 1495914965.

(63) Sivanandam, V. N.; Jayaraman, M.; Hoop, C. L.; Kodali, R.; Wetzel, R.; van der Wel, P. C., The Aggregation-Enhancing Huntingtin N-Terminus Is Helical in Amyloid Fibrils. J. Am. Chem. Soc. 2011, 133, 4558-4566.

(64) Lovell, S. C.; Davis, I. W.; Arendall, W. B., 3rd; de Bakker, P. I.; Word, J. M.; Prisant, M. G.; Richardson, J. S.; Richardson, D. C., Structure Validation by Calpha Geometry: Phi,Psi and Cbeta Deviation. Proteins 2003, 50, 437-450.

(65) Blanch, E. W.; Morozova-Roche, L. A.; Cochran, D. A.; Doig, A. J.; Hecht, L.; Barron, L. D., Is Polyproline Ii Helix the Killer Conformation? A Raman Optical Activity Study of the Amyloidogenic Prefibrillar Intermediate of Human Lysozyme. J. Mol. Biol. 2000, 301, 553-563.

(66) Bielska, A. A.; Zondlo, N. J., Hyperphosphorylation of Tau Induces Local Polyproline Ii Helix. Biochemistry 2006, 45, 5527-5537.

(67) Hejjaoui, M.; Butterfield, S.; Fauvet, B.; Vercruysse, F.; Cui, J.; Dikiy, I.; Prudent, M.; Olschewski, D.; Zhang, Y.; Eliezer, D., et al., Elucidating the Role of C-Terminal PostTranslational Modifications Using Protein Semisynthesis Strategies: Alpha-Synuclein Phosphorylation at Tyrosine 125. J. Am. Chem. Soc. 2012, 134, 5196-5210.

(68) Proctor, E. A.; Ding, F.; Dokholyan, N. V., Structural and Thermodynamic Effects of Post-Translational Modifications in Mutant and Wild Type $\mathrm{Cu}, \mathrm{Zn}$ Superoxide Dismutase. $J$. Mol. Biol. 2011, 408, 555-567.

(69) Giannopoulos, P. N.; Robertson, C.; Jodoin, J.; Paudel, H.; Booth, S. A.; LeBlanc, A. C., Phosphorylation of Prion Protein at Serine 43 Induces Prion Protein Conformational Change. $J$. Neurosci. 2009, 29, 8743-8751. 
For Table of Contents Only



